\title{
The influence of domain size on the response characteristics of a hurricane storm surge model
}

\author{
C. A. Blain and J. J. Westerink \\ Department of Civil Engineering and Geological Sciences, \\ University of Notre Dame, Notre Dame, Indiana
}

\author{
R. A. Luettich Jr. \\ University of North Carolina at Chapel Hill, Institute of Marine Sciences, Morehead City
}

\begin{abstract}
The influence of domain size on boundary condition specification and on computed storm surge response is investigated. Storm surge response along the Florida shelf in the Gulf of Mexico due to Hurricane Kate is examined over three domains using two different open ocean boundary forcing functions, a still water (or zero elevation) condition and an inverted barometer condition which accounts for the atmospheric pressure component of the meteorological forcing. The first domain is relatively small and is situated primarily on the continental shelf in the region of intense storm surge generation. A second domain includes the entire Gulf of Mexico basin. The final domain covers the Gulf of Mexico, contiguous basins, and extends out into the deep Atlantic Ocean. The computed storm surge response indicates that the small domain is inadequate, since cross-shelf boundaries are in regions of significant storm surge generation where surge and therefore boundary conditions are not known a priori. Also, the behavior of resonant modes that are physically excited within the Gulf of Mexico due to the passage of the hurricane is unknown at the boundaries of this small domain. The domain that includes the entire Gulf of Mexico captures the primary storm surge well but may not correctly model resonant modes. In general, these resonant modes are difficult to accurately set up by boundary condition specification, since they may be dependent on interactions between the Gulf and contiguous basins. The primary storm surge response as well as resonant modes excited by the storm are best represented using a domain which encompasses the western North Atlantic Ocean, the Caribbean Sea, and the Gulf of Mexico. This domain with deep Atlantic Ocean boundaries facilitates simple boundary condition specification and minimizes the influence of boundary conditions on storm surge generation in coastal regions. Basin resonant modes and basin to basin interactions are also captured.
\end{abstract}

\section{Introduction}

Numerical modeling has become a widely used tool for assessing the physics of continental margin waters. It is important to recognize that the computed response of these waters is controlled by the various components which make up a model, including the governing equations, the boundary conditions, the forcing functions, the numerics, the grid structure, and the computational domain itself. A major shortcoming in coastal ocean modeling work is the lack of adequate studies to prove convergence with regard to grid structure, grid spacing, and domain size. As a result, it is often unclear whether computed water body responses are significantly aliased due to inadequate grid resolution or are overwhelmed by the imposed boundary conditions and their interactions with the selected domain. Only recently have there been efforts to establish the level to which the computed physics has converged by doing

Copyright 1994 by the American Geophysical Union.

Paper number 94JCO1348.

0148-0227/94/94JC-01348\$05.00 systematic grid convergence studies for tidal, wind-driven, and large-scale baroclinic circulation [Le Provost and Vincent, 1986; Bennett and Campbell, 1987; Dietrich et al., 1990; Piacsek and Allard, 1993; Dietrich, 1993; Westerink et al., 1994]. The primary focus of this brief report is to investigate the influence of domain size on hurricane storm surge response.

For this study, an actual hurricane that made landfall on the Florida shelf in the Gulf of Mexico is applied over three domains. Each domain has a different size fanning out from the point of hurricane landfall and covering successively larger regions. The first domain is a relatively small coastal domain which extends mainly over the continental shelf. A second domain covers the entire Gulf of Mexico basin. The final domain extends well into the deep Atlantic Ocean. Two different elevation boundary conditions are considered in the simulations, a still water condition and a condition that incorporates the atmospheric pressure component of the meteorological forcing. Comparisons are made between storm surge elevations computed over all three domains using both boundary conditions to determine the influence of domain size and the sensitivity to boundary condition specification on storm surge response. 


\section{Hydrodynamic Model Description}

The hydrodynamic computations were performed using ADCIRC-2DDI, the depth integrated option of a set of twoand three-dimensional fully nonlinear hydrodynamic codes named ADCIRC [Luettich et al., 1992]. ADCIRC-2DDI uses the vertically averaged equations of mass and momentum conservation, subject to the hydrostatic pressure approximation. For the applications in this paper, we used the standard quadratic parameterization for bottom stress and neglected the baroclinic terms, the finite amplitude terms, as well as the advective and lateral diffusion/dispersion terms, leading to the following set of conservation statements in primitive, nonconservative form expressed in a spherical coordinate system [Kolar et al., 1994a]:

$$
\begin{gathered}
\frac{\partial \zeta}{\partial t}+\frac{1}{R \cos \phi}\left[\frac{\partial U h}{\partial \lambda}+\frac{\partial(V h \cos \phi)}{\partial \phi}\right]=0 \\
\frac{\partial U}{\partial t}-2 \Omega \sin \phi V=-\frac{1}{R \cos \phi} \frac{\partial}{\partial \lambda}\left[\frac{p_{s}}{\rho_{0}}+g \zeta\right]+ \\
\frac{\tau_{s \lambda}}{\rho_{0} h}-\tau_{*} U \\
\frac{\partial V}{\partial t}+2 \Omega \sin \phi U=-\frac{1}{R} \frac{\partial}{\partial \phi}\left[\frac{p_{s}}{\rho_{0}}+g \zeta\right]+ \\
\frac{\tau}{\rho_{0} h}-\tau_{*} V
\end{gathered}
$$

where $t$ represents time, $\lambda, \phi$ are degrees longitude (east of Greenwich positive) and degrees latitude (north of the equator positive), $\zeta$ is the free surface elevation relative to the geoid, $U, V$ are the depth-averaged horizontal velocities, $R$ is the radius of the Earth, $h$ is the bathymetric depth relative to the geoid, $\Omega$ is the angular speed of the Earth, $p_{s}$ is the atmospheric pressure at the free surface, $g$ is the acceleration due to gravity, $\rho_{0}$ is the reference density of water, $\tau_{s \lambda}, \tau_{s \phi}$ are the applied free surface stresses, and $\tau_{*}$ is given by the expression $C_{f}\left(U^{2}+V^{2}\right)^{1 / 2} / h$, where $C_{f}$ equals the bottom friction coefficient.

Equations (1)-(3) are reformulated into a generalized wave continuity equation (GWCE) and are subsequently discretized using the finite element (FE) method [Lynch and Gray, 1979; Lynch, 1983; Kinnmark, 1984; Westerink and Gray, 1991]. ADCIRC-2DDI has been implemented using linear, triangular finite elements. The details of ADCIRC-2DDI are described by Luettich et al. [1992], Kolar et al. [1994a,b], and Westerink et al. [1994]. It is noted that shoreline wetting and/or drying is not currently accommodated in the code. In fact, near-drying elements require the linearizations which are applied for the simulations described in this paper.

\section{Meteorological Forcing}

Computations of hurricane wind stress and pressure fields are carried out using a modified form of the HURWIN wind model [Cardone et al., 1992]. An exponential pressure law is used in the HURWIN model to generate a circularly symmetric pressure field situated at the low-pressure center of the storm:

$$
p_{s}=p_{\text {eye }}+\Delta p e^{-(R / r)}
$$

where $p_{s}$ is the spatially and temporally varying pressure field, $p_{\text {eye }}$ is the pressure at the center or eye of the storm, $\Delta p=\bar{p}-p_{\text {eye }}$ is the pressure anomaly with $\bar{p}$ taken as an average background pressure, and $r$ is the radial distance outward from the eye of the storm. The scale radius, $R$, often assumed equivalent to the radius to maximum wind, is computed from an approximation of a nomograph relating $R$ to the maximum wind speed and the pressure anomaly, $\Delta p$ [Jelesnianski and Taylor, 1973]. Wind speed computed within the HURWIN model is obtained through a solution of the equations of horizontal motion which have been vertically averaged through the depth of the planetary boundary layer. These wind speeds are then converted to surface wind stresses using a quadratic drag law proposed by Garratt [1977].

For all simulations presented in this brief report, Hurricane Kate is the historical storm that serves as the meteorological forcing for the hydrodynamic model. The track of Hurricane Kate through the westem North Atlantic Ocean and the Gulf of Mexico is shown at 6 hour increments in Figure 1. The HURWIN model simulation of Hurricane Kate began at 1800 UT November 15, 1985, and ended 8 days later at 1800 UT November 23, 1985. During this period the forward speed of Hurricane Kate ranged from $1.5 \mathrm{~m} \mathrm{~s}^{-1}$ to $13.4 \mathrm{~m} \mathrm{~s}^{-1}$ and the radius to maximum wind varied between $80 \mathrm{~km}$ and $17 \mathrm{~km}$. Throughout the HURWIN model simulation, a constant background pressure of 1013 mbar was assumed. All other parameters pertaining to Hurricane Kate were obtained from the HURDAT tape [Jarvinen et al., 1993] which documents the movement and characteristics of historical hurricanes.

\section{Hydrodynamic Domain Descriptions}

Three hydrodynamic domains of widely varied sizes are considered in our investigation. The domain sizes are selected to clearly demonstrate the relationship between the domain and open ocean boundary elevation specification. The two smaller domains are constructed to correspond with domains used in recent storm surge modeling efforts. All domains used here expand outward from the landfall region of Hurricane Kate near Panama City, Florida, and cover increasingly larger areas. The exact areal extent of each domain as well as other characteristics pertinent to the domains and their discretizations are summarized in Table 1.

The smallest domain considered is the Florida coast domain pictured in Figure 2a. The Florida coast domain is a semicircular basin similar to the one used by the National Weather Service at Pensacola Bay in conjunction with the SLOSH storm surge model [Jarvinen and Lawrence, 1985; Jelesnianski et al., 1992]. The Florida coast domain extends radially outward into the Gulf of Mexico from the shoreline surrounding Panama City, Florida, with a radius of approximately $175 \mathrm{~km}$. The outer arc of the semicircular basin forms the open ocean boundary of the domain. Bathymetric data for the Florida coast domain, shown in Figure 2a, is obtained from the topographic database ETOPO5 from the National Center for Atmospheric Research and supplemented by the NOAA Digital U.S. Coastal Hydrography sounding data base. A minimum depth of $3 \mathrm{~m}$ is imposed throughout the Florida coast domain to eliminate complete drying in computational elements along the shore and in embayments. A maximum depth of nearly $1100 \mathrm{~m}$ is recorded at the outer limit of the Florida coast domain, but as is seen in Figure 2a, much of the 


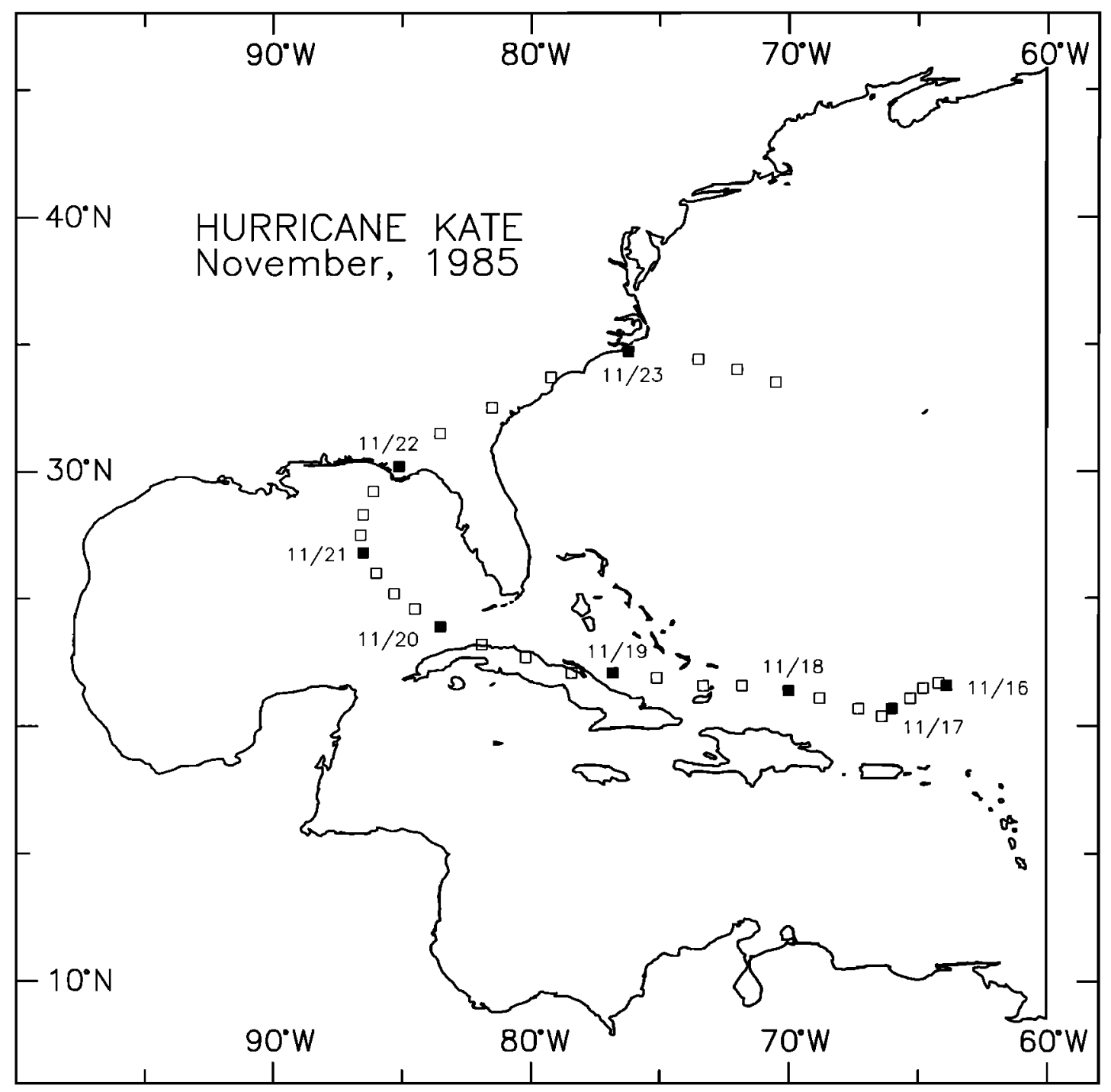

Figure 1. Track of Hurricane Kate through the western North Atlantic Ocean into the Gulf of Mexico from 1800 UT November 15, 1985 to 1800 UT November 23, 1985.

Florida coast domain lies on the continental shelf at depths less than $130 \mathrm{~m}$. The discretization of the Florida coast domain is shown in Figure $3 a$.

The second domain, the Gulf of Mexico domain shown in Figure 2b, includes the entire Gulf of Mexico and is similar to domains used by several other investigators for storm surge modeling studies within the Gulf of Mexico [e.g., Bunpapong et al., 1985]. The Gulf of Mexico domain is comprised of the
Florida coast domain and all surrounding regions in the Gulf of Mexico. One open ocean boundary is located across the Strait of Florida (approximately from Cape Sable, Florida, to Havana, Cuba) and another is located across the Yucatan Channel (approximately from Cancun, Mexico, to Cabo San Antonio, Cuba). Bathymetry in the Gulf of Mexico domain, depicted in Figure $2 b$, is taken from the ETOPO5 database, and in regions along the Florida coast and shelf it is supple-

Table 1. Characteristics of the Model Domains

\begin{tabular}{|c|c|c|c|c|c|c|}
\hline \multirow{2}{*}{ Domain } & \multirow{2}{*}{$\begin{array}{l}\text { Area, } \\
\mathbf{k m}^{2}\end{array}$} & \multirow{2}{*}{$\begin{array}{c}\text { Maximum } \\
\text { Depth, } \\
\text { m }\end{array}$} & \multicolumn{2}{|c|}{ Discretization } & \multicolumn{2}{|c|}{ Grid Size, km } \\
\hline & & & Nodes & Elements & Maximum & Minimum \\
\hline Florida coast & $5.07 \times 10^{4}$ & 1,094 & 1,451 & 2,326 & 32.5 & 0.5 \\
\hline Gulf of Mexico & $1.41 \times 10^{6}$ & 3,781 & 6,325 & 11,441 & 50.0 & 0.5 \\
\hline Eastcoast & $8.35 \times 10^{6}$ & 7,765 & 23,711 & 41,709 & 105.0 & 0.5 \\
\hline
\end{tabular}




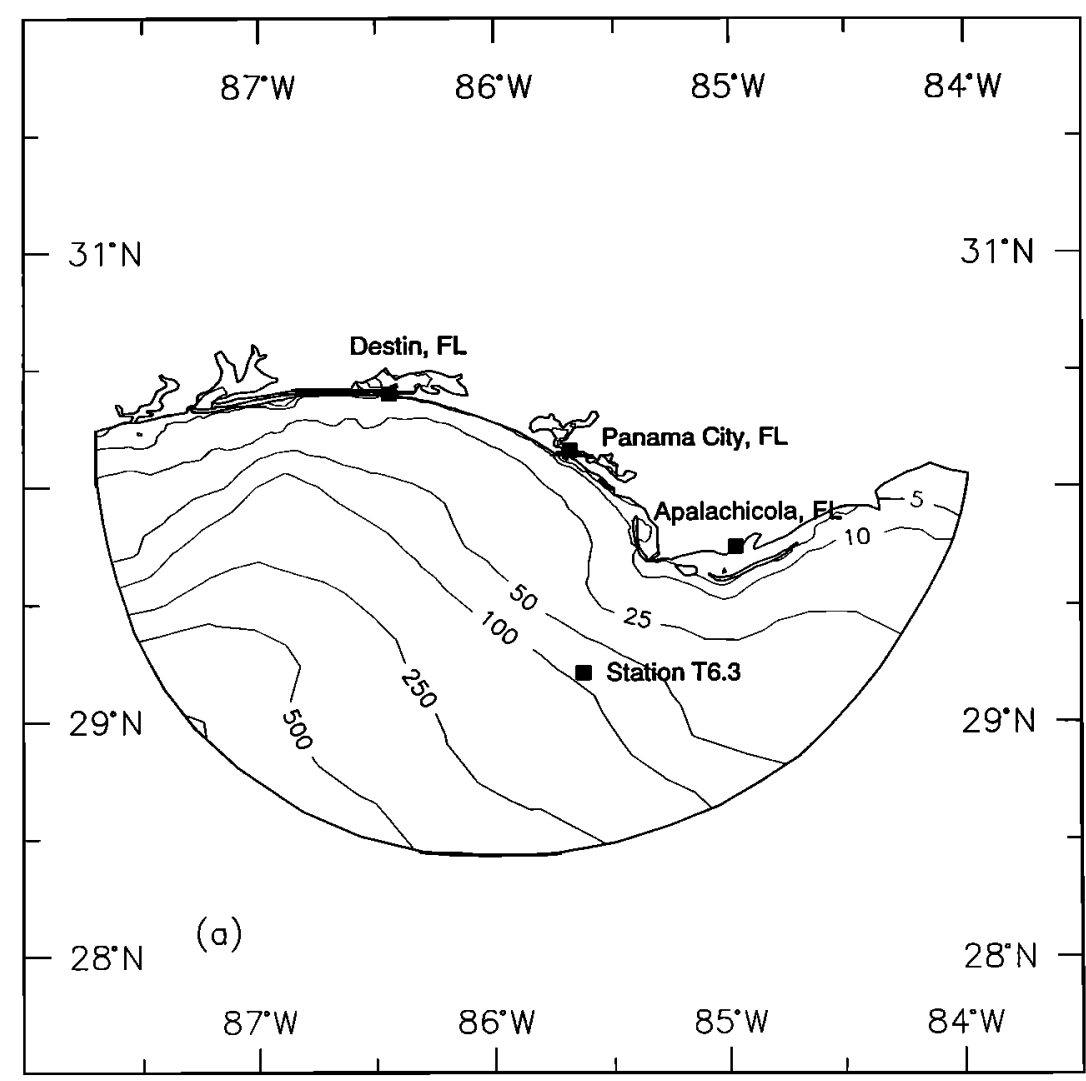

Figure 2a. Bathymetry contours for the Florida coast domain and elevation station names and locations.

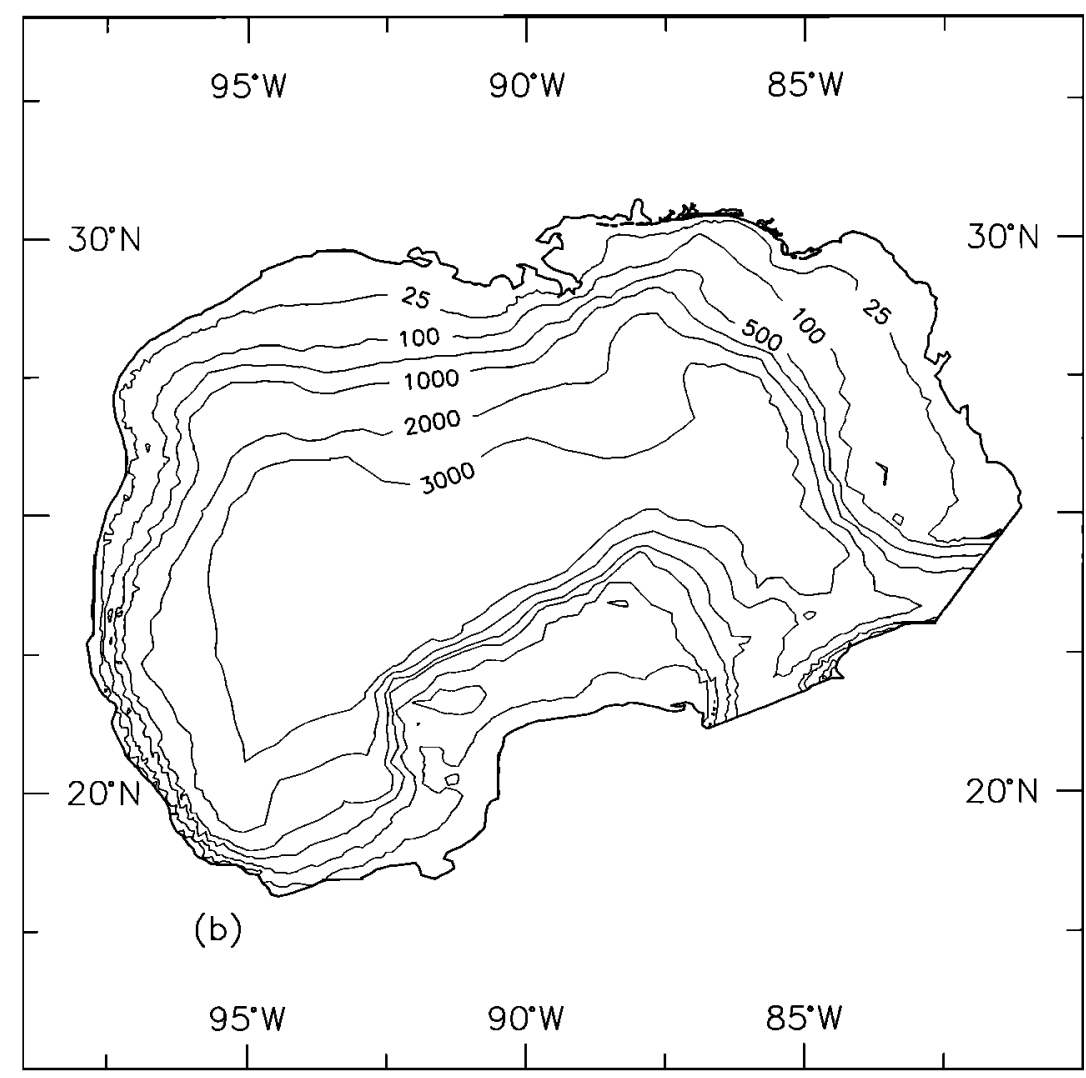

Figure 2b. Bathymetry contours for the Gulf of Mexico domain. 


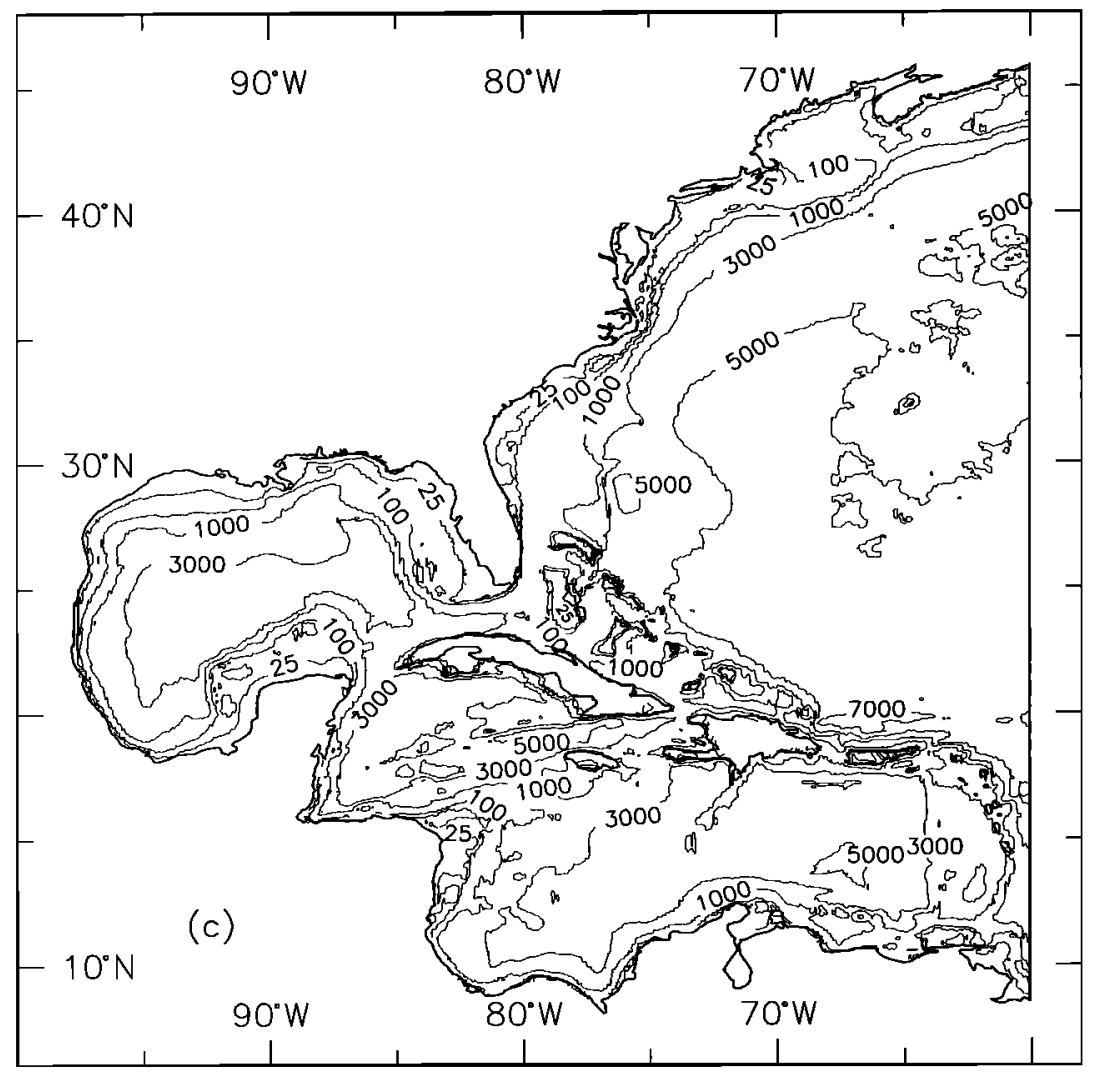

Figure 2c. Bathymetry contours for the Eastcoast domain.

mented by the NOAA Digital U.S. Coastal Hydrography sounding database. In the region of the Gulf of Mexico domain which corresponds to the Florida coast domain, the topography is identical to that specified for the Florida coast domain. The discretization of the Gulf of Mexico domain is presented in Figure 3b. In the region encompassing the Florida coast domain, the discretization of the Gulf of Mexico domain is the same as that in the Florida coast domain.

The final and largest domain is the Eastcoast domain shown in Figure 2c, which has been previously used by Westerink et al. [1994] to study tides in the westem North Atlantic. The Eastcoast domain encompasses the western North Atlantic Ocean, the Caribbean Sea, and the Gulf of Mexico and has been constructed such that both the Gulf of Mexico and Florida coast domains are contained within the Eastcoast domain. A single deep Atlantic Ocean boundary within the Eastcoast domain extends from Glace Bay, Nova Scotia, to the vicinity of Corocora Island in eastern Venezuela along the $60^{\circ} \mathrm{W}$ meridian. All other boundaries are defined by the eastern coastlines of North, Central, and South America. Topography within the domain is depicted in Figure 2c. Depths within the Gulf of Mexico region are the same as those specified for the Gulf of Mexico domain. Bathymetry in regions outside the Gulf of Mexico was obtained from the ETOP05 database. The discretization of the Eastcoast domain is shown in Figure 3c.

\section{Comparison of Storm Surge Predictions Using Three Domain Sizes}

A series of simulations is conducted to investigate the influence of domain size and boundary condition specification on the storm surge and resonant mode generation associated with Hurricane Kate. Domain size is considered using the three previously described domains. Boundary condition specification is examined by comparing a still water boundary condition where water elevation is set equal to the mean sea level with a boundary condition that partially accounts for meteorological forcing by imposing an inverted barometer effect. An inverted barometer, $p_{s} / \rho_{0} g$, is simply the height to which seawater will rise due to pure static pressure forcing. For all of these simulations, wind stress and pressure forcing are applied on the interior of the domain, and tidal forcing is neglected both on the interior and at the open ocean boundaries.

Model parameters are identical for all simulations, so that comparisons between the results for different domains using each boundary condition is possible. The convective and finite amplitude terms are not included in the governing equations for these simulations due to instabilities caused by near-drying elements. Consequently, the only nonlinear term included in the governing equations is bottom friction. The bottom friction coefficient is constant and equal to 0.003 over all domains.

Simulations are spun up from homogeneous initial conditions using a 1-day hyperbolic ramp in time that reduces the excitation of nonphysical short-wavelength frequencies. An identical ramp function of 1-day length is applied to the wind and pressure forcing as well as the inverted barometer boundary condition when used. Actual simulations begin at 1200 UT November 15 and run over 8.25 days (including the 1-day ramp-up period). During the first 6 hours of the simulation, the initial hurricane wind and pressure forcings are held stationary. Thereafter, storm surge computations use the timevarying wind and pressure fields. A time step of $45 \mathrm{~s}$ is used 


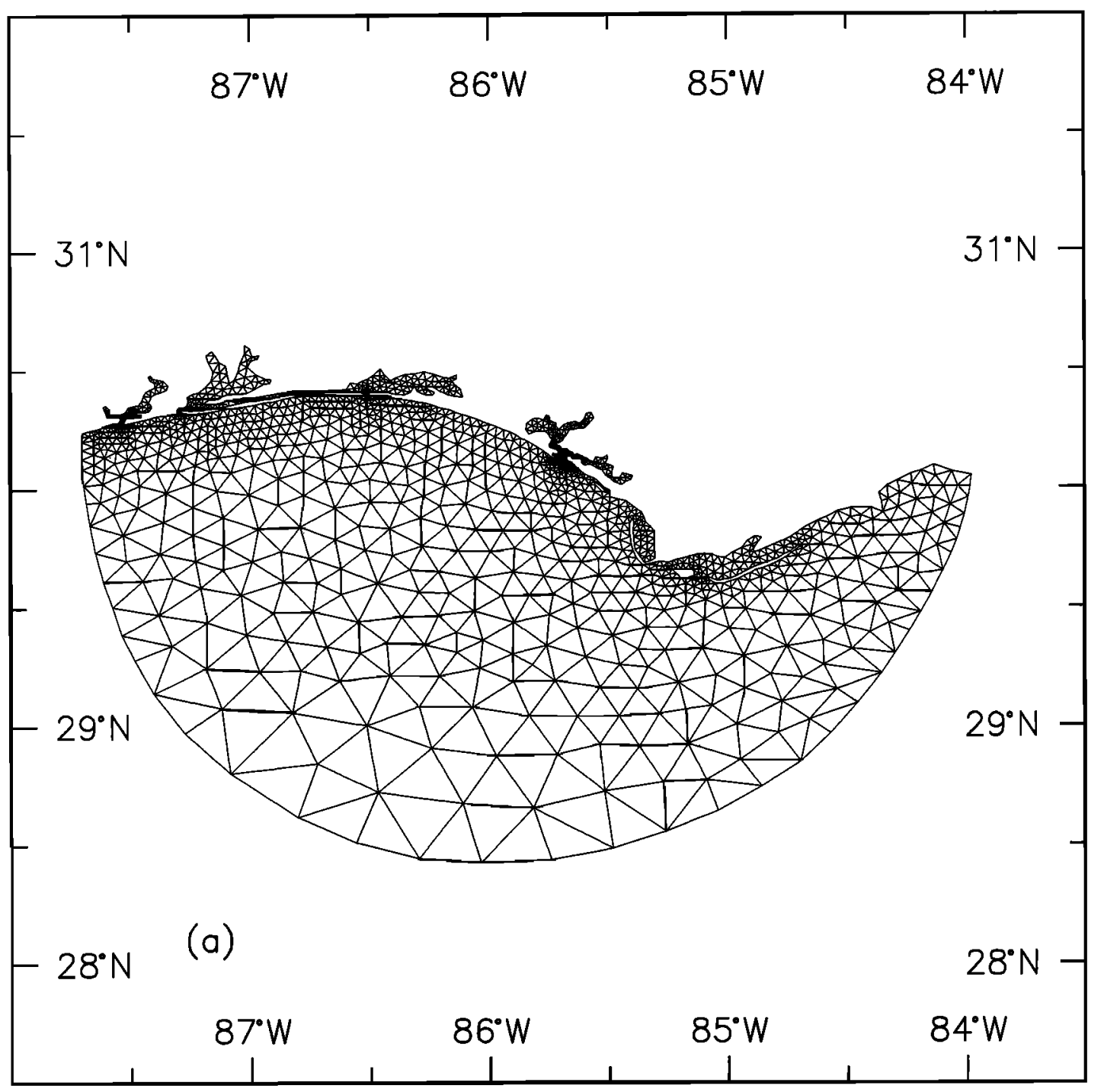

Figure 3a. The Florida coast domain discretization.

throughout the simulation period. No calibration or tuning of parameters is performed in either the weather model or the hydrodynamic model.

The storm surge response is examined at three stations along the Florida coast, Apalachicola, Destin, and station T6.3, all shown in Figure 2a. Computed storm surge hydrographs at these stations are shown in Figures 4a-6a using a still water boundary condition and in Figures $4 b-6 b$ using an inverted barometer boundary condition. The storm surge profile at Apalachicola is representative of conditions on the right-hand side of the hurricane. Storm surge elevations at Destin exhibit behavior characteristic of the left-hand side of the hurricane. Station T6.3 is located on the continental shelf approximately $15 \mathrm{~km}$ from the shelf break.

In all of the storm surge hydrographs in Figures 4-6, the peak surge for the Gulf of Mexico and Eastcoast domains closely correspond, whereas the elevation response computed over the Florida coast domain is significantly smaller, particularly on the right-hand side of the hurricane. Furthermore, Figures 4-6 indicate that all three stations exhibit different oscillatory patterns or modes in the storm surge response between the Eastcoast and Gulf of Mexico domains regardless of the open boundary condition imposed. However, for the Gulf of Mexico domain, these modes are more pronounced when a still water boundary condition is used (Figures 4a-6a) than when the inverted barometer boundary condition is implemented (Figures 4b-6b). The modes in the Eastcoast domain solution in Figures 4-6 exhibit no sensitivity to boundary condition specification. Since all domains have identical discretizations over corresponding regions and simulations were conducted using identical model parameters and wind and pressure forcing, differences between the model responses are due solely to the domain size and/or the boundary condition specification.

To investigate the origin of the differences in the storm surge response over the three domains, elevation contours showing the progression of Hurricane Kate through the Gulf of Mexico toward Panama City are shown in Figures 7a, 7b, and 7c for successive time periods. At 2000 UT November 20 , 1985 (Figure 7a), a widespread inverted barometer centered at the hurricane eye is evident. Already water is accumulating and elevation is increasing in the northeastern Gulf of Mexico, especially on the northeast Florida shelf. Ten hours later at 0600 UT November 21, 1985 (Figure 7b), as the eye of the 


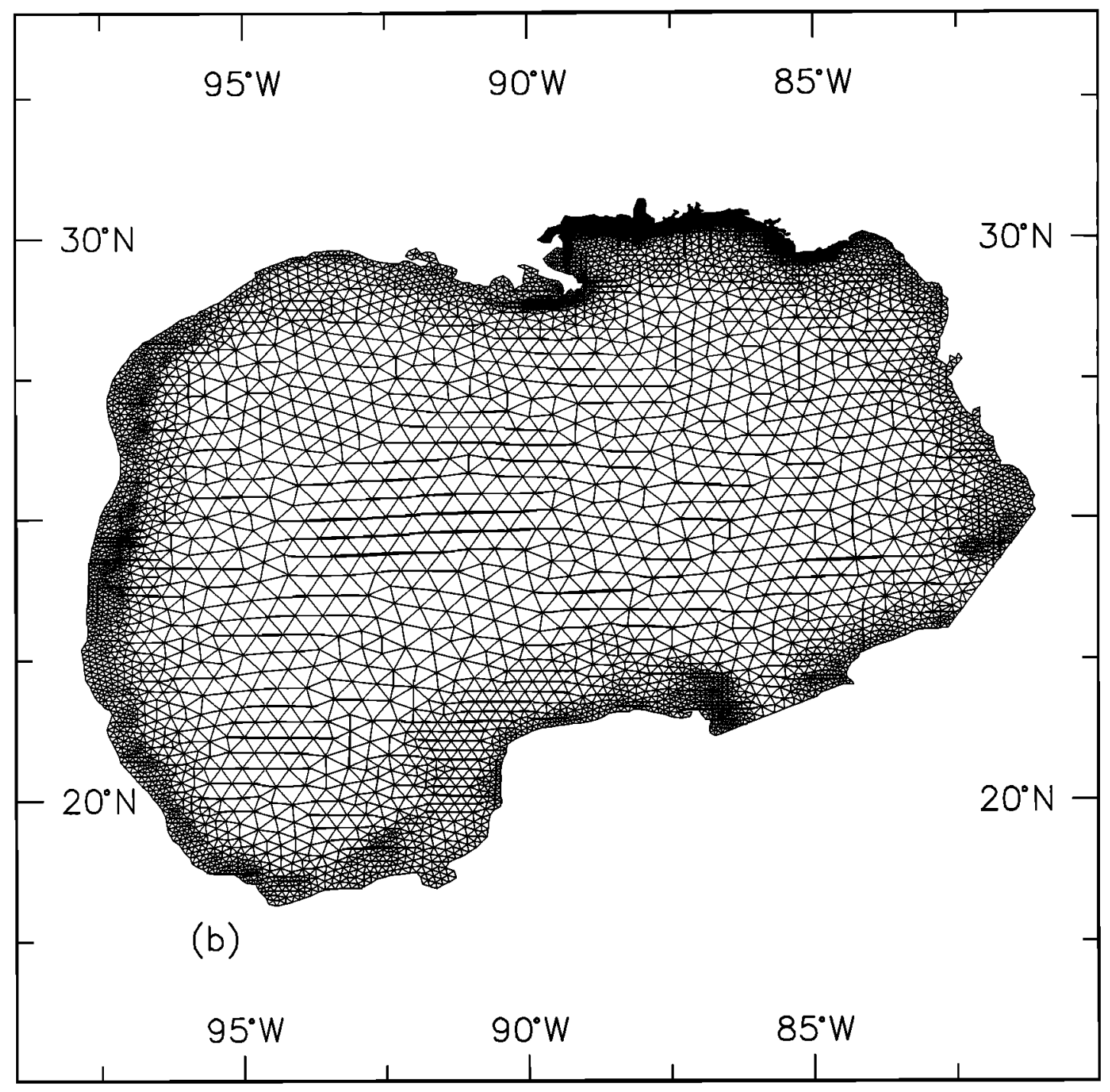

Figure 3b. The Gulf of Mexico domain discretization.

hurricane approaches the Florida shelf, the inverted barometer effect has diminished and its structure is deteriorating. High water elevations on the shelf, particularly in shallow coastal areas, indicate that hurricane winds have pushed water up on the continental shelf. The last snapshot, shown in Figure $7 \mathrm{c}$, is taken 8 hours prior to landfall of the hurricane at 1800 UT November 21, 1985. Hurricane Kate is now on the continental shelf and the surface elevation response no longer exhibits any inverted barometer structure. Water continues to pile up over an extensive region on the shelf in a pronounced way on the right-hand side of the hurricane.

The Florida coast domain is located almost entirely within the region of intense storm surge generation shown in Figure 7. In particular, the cross-shelf boundaries of the Florida coast domain are located in an area of significant surge where hurricane winds have driven water up onto the shelf. Even an inverted barometer forcing specified at these cross-shelf boundaries significantly underestimates storm surge elevations which physically occur at these boundaries and are represented using the Gulf of Mexico and Eastcoast domains. Since, the storm surge generated on the shelf by hurricane winds is not known a priori, an appropriate elevation boundary condition cannot be specified at cross-shelf boundaries, which comprise nearly the entire boundary of the small shelf domain. Consequently, a domain, such as the Florida coast domain, which is small in size relative to the spatial scale of a hurricane and is located primarily on the continental shelf cannot be used to obtain a physically relevant storm surge response.

The oscillatory behavior of the storm surge elevations or surge forerunner effect computed over the Eastcoast and Gulf of Mexico domains exhibited in Figures 4-6 can be attributed to basinwide resonant modes which exist in the Gulf of Mexico as documented by Platzman [1972], Reid and Whitaker [1981], and Bunpapong et al. [1985]. These modes are not excited in the Florida coast domain due to the small size of the domain and the omission of the shelf to adjacent basin interaction in the specified boundary forcing. On the contrary, resonant modes are excited in the Gulf of Mexico domain. In fact, open ocean boundary elevations specified at entrances to the Gulf of Mexico significantly influence the setup of modes in the Gulf of Mexico. This is demonstrated in Figures 4-6 for the Gulf of Mexico domain, where oscillations in water level are more pronounced when using a still water boundary condition (Figures 4a-6a) than an inverted barometer 


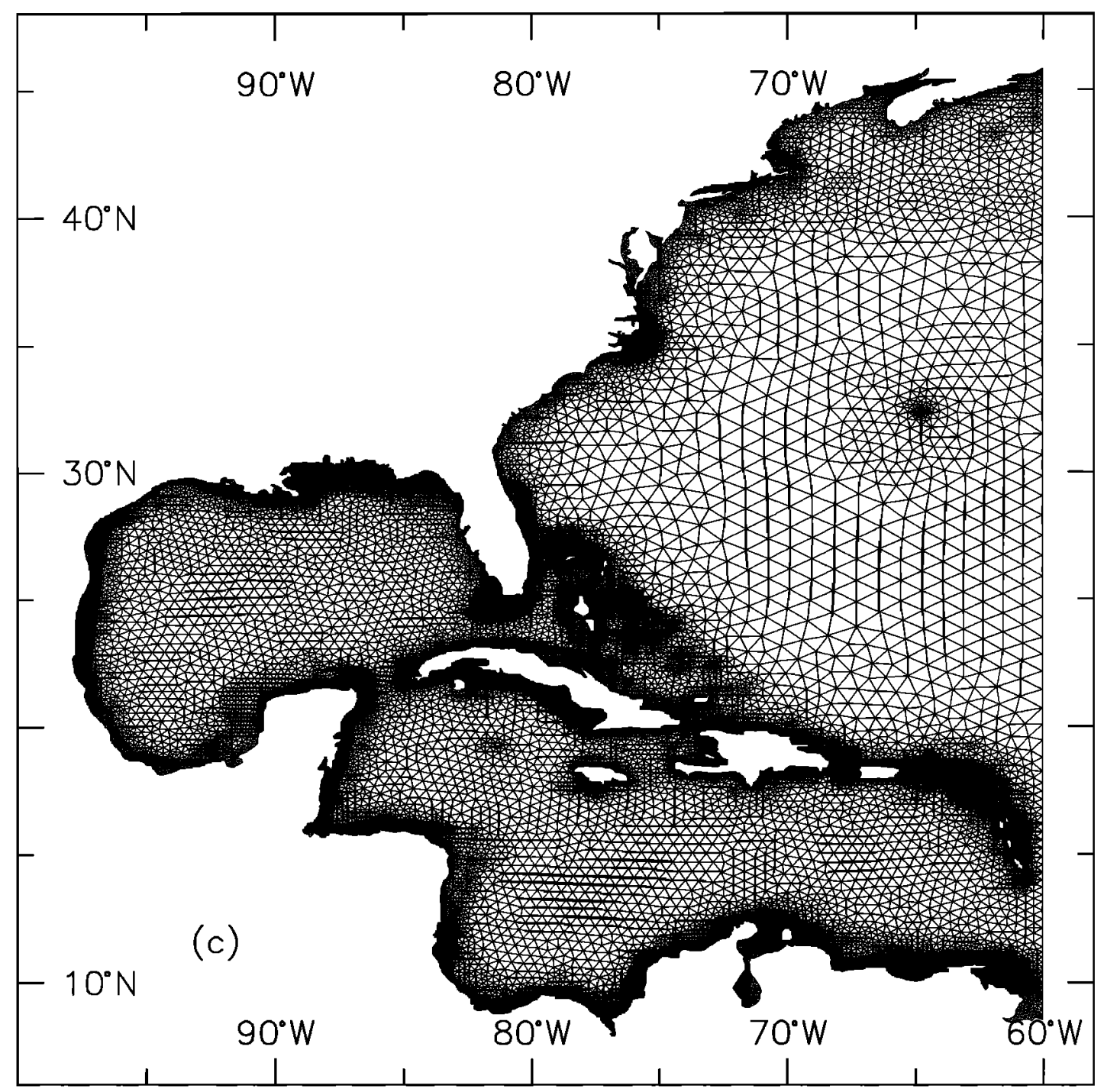

Figure 3c. The Eastcoast domain discretization.

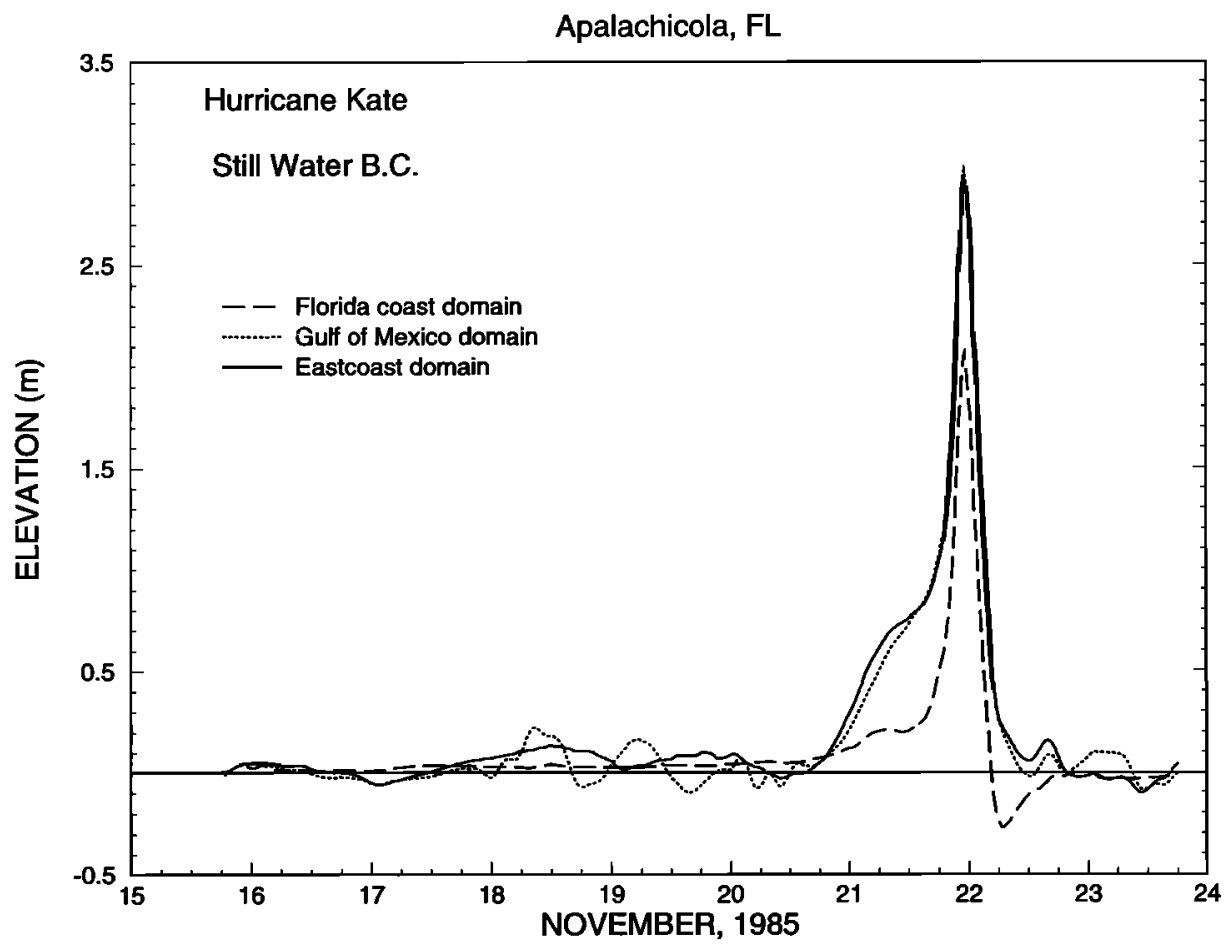

Figure 4a. Computed storm surge for Hurricane Kate using a still water open boundary condition at Apalachicola, Florida. 
Apalachicola, FL

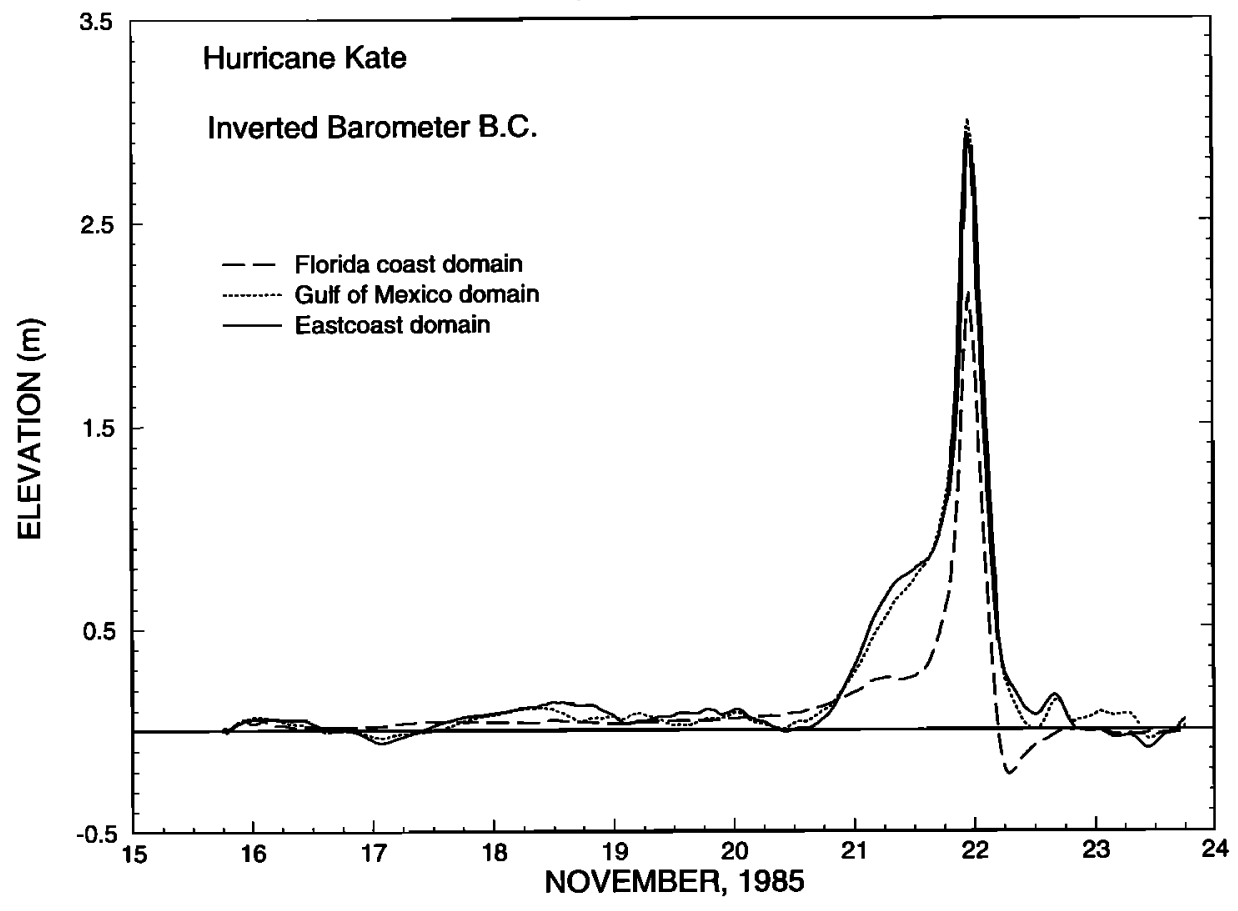

Figure 4b. Computed storm surge for Hurricane Kate using an inverted barometer open boundary condition at Apalachicola, Florida.

boundary condition (Figures 4b-6b). Platzman [1972] and Reid and Whitaker [1981] also found that the frequency of the modes in the Gulf of Mexico varied with the application of different boundary conditions. One concludes, then, that the resonant modes in the Gulf of Mexico may be difficult to model with the Gulf of Mexico domain due to the sensitivity of these modes to boundary condition specification and the associated shortcomings in the representation of basin to basin dynamics.

A comparison of water level response at all three stations using the two different elevation conditions along the Eastcoast domain open ocean boundary clearly demonstrates that the influence of boundary condition specification is minimized when using the Eastcoast domain. This insensitivity to the

Destin, FL

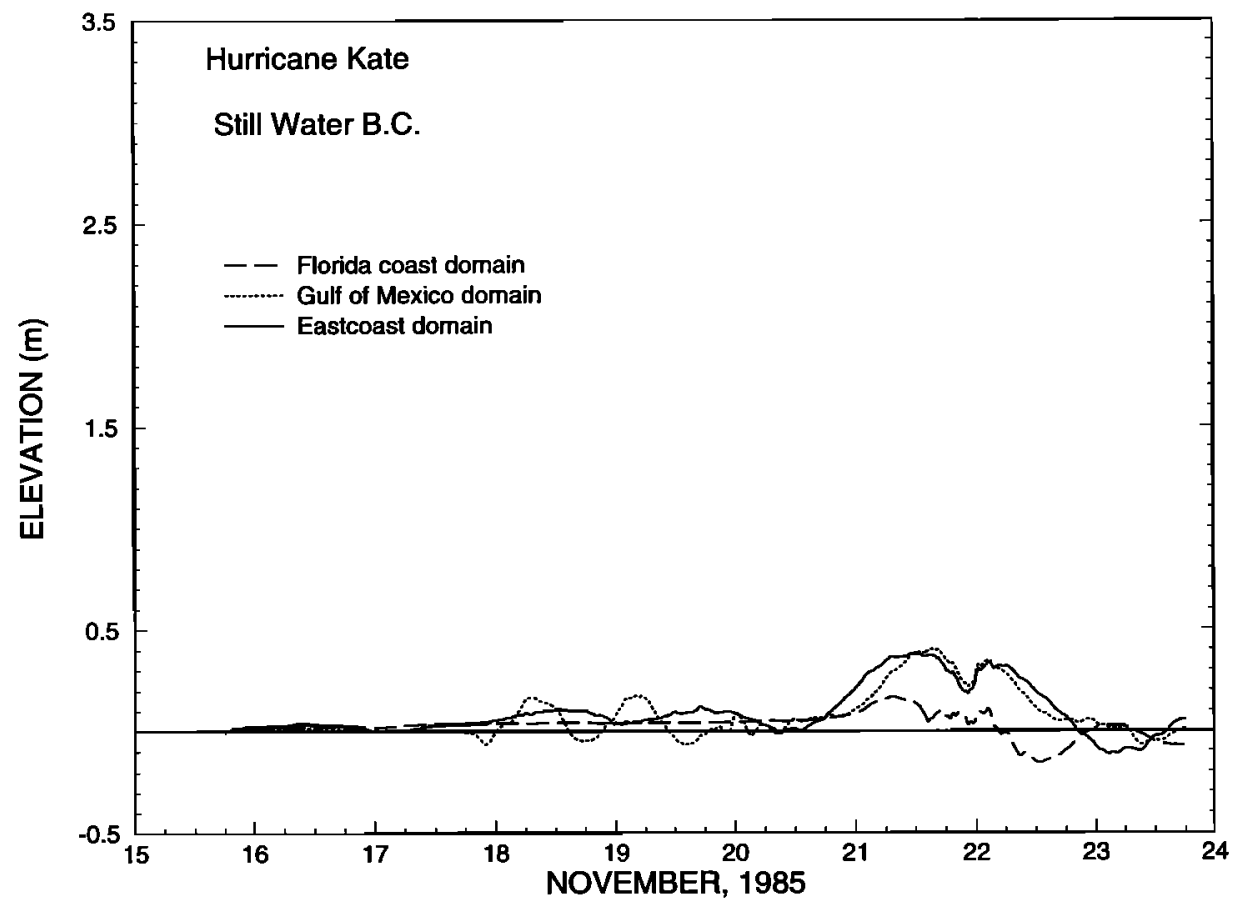

Figure 5a. Computed storm surge for Hurricane Kate using a still water open boundary condition at Destin, Florida. 


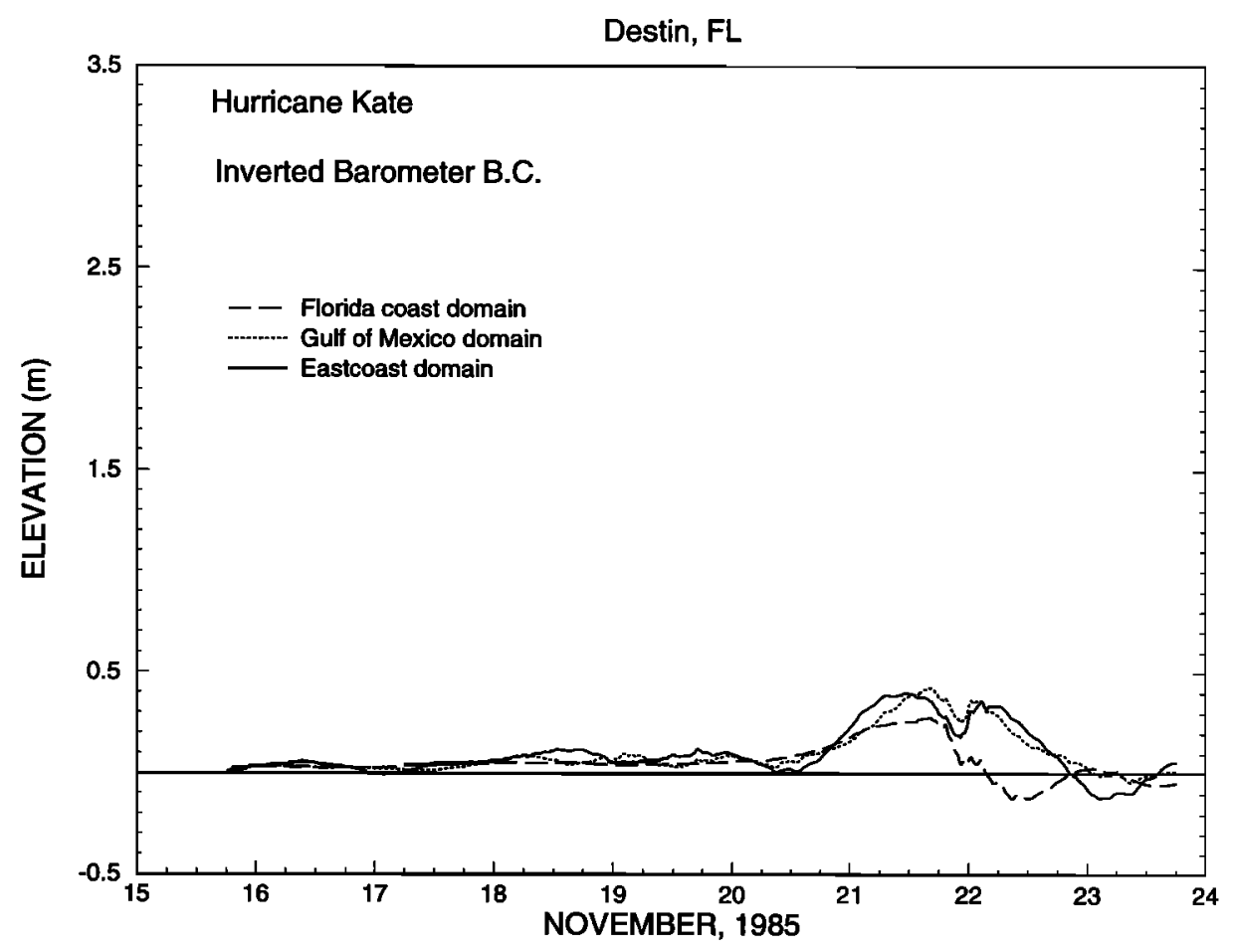

Figure 5b. Computed storm surge for Hurricane Kate using an inverted barometer open boundary condition at Destin, Florida.

specification of boundary conditions in the deep Atlantic as well as the fact that basin to basin interactions are more faithfully represented suggest that the flow physics at this boundary need not be precisely known and resonant modes in the Gulf of Mexico are properly set up using the Eastcoast domain.

\section{Conclusions}

Previously, little effort has been made to understand the relationship between domain size, boundary conditions, and the resulting physics for storm surge modeling in continental

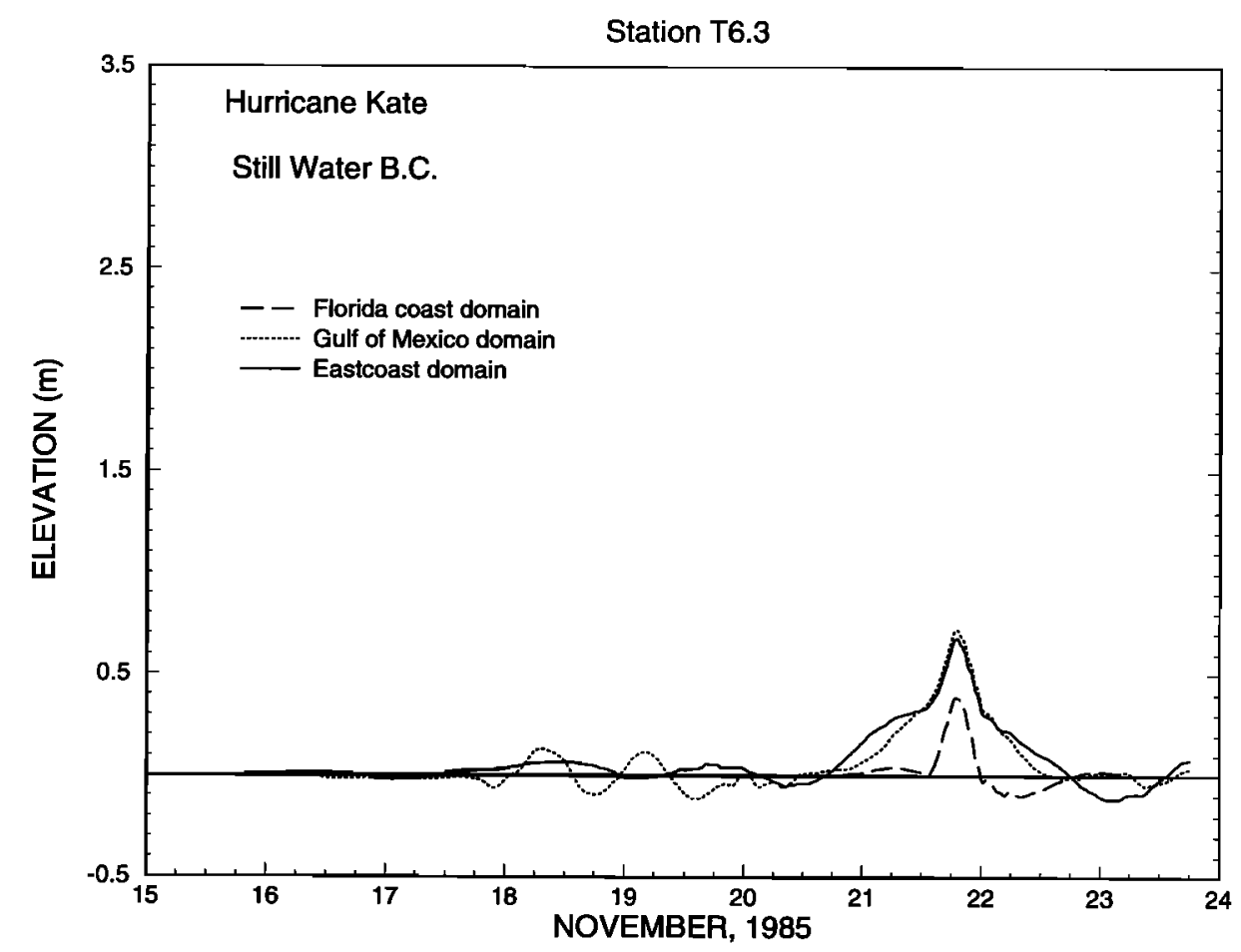

Figure 6a. Computed storm surge for Hurricane Kate using a still water open boundary condition at station T6.3. 
Station T6.3

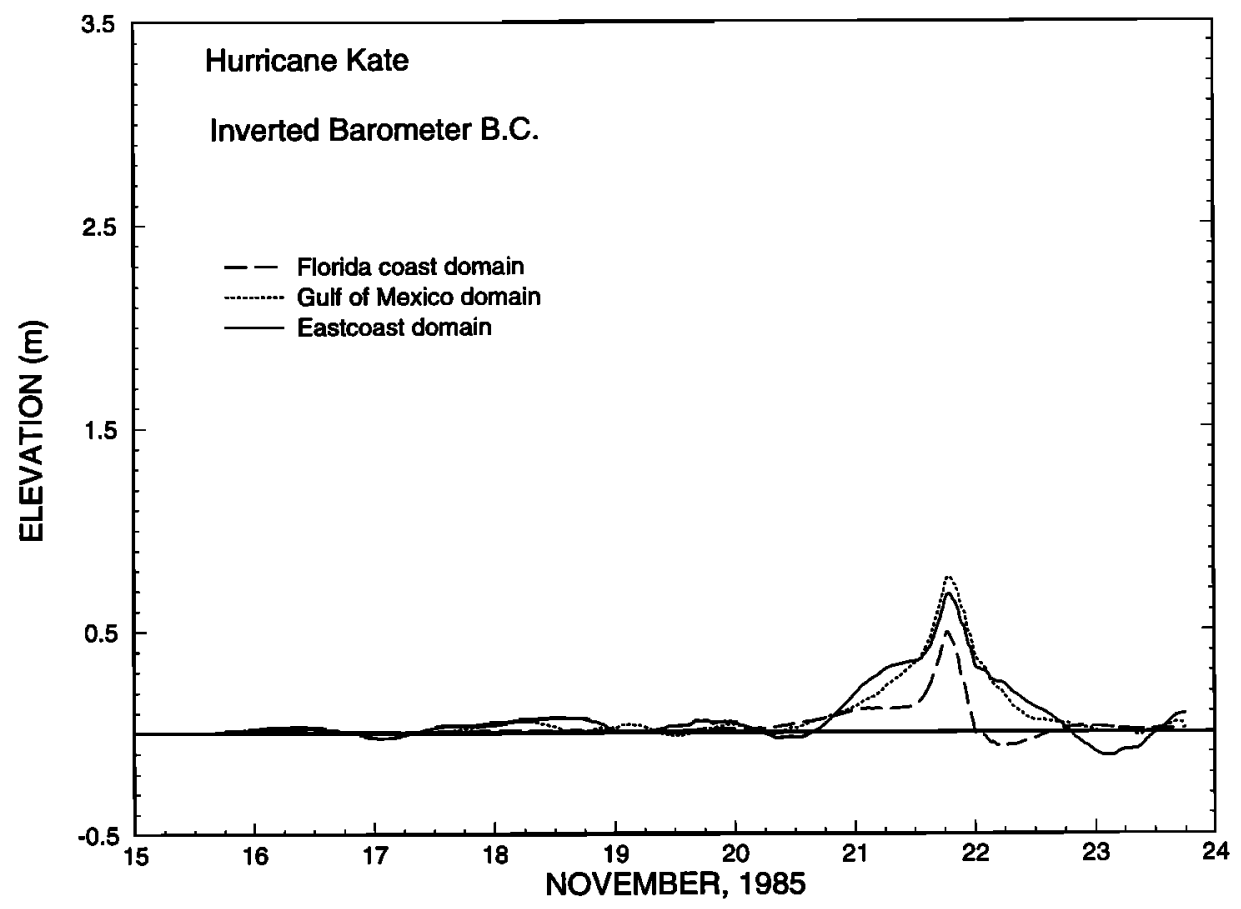

Figure 6b. Computed storm surge for Hurricane Kate using an inverted barometer open boundary condition at station T6.3.

margin waters. In this brief report, hurricane storm surge computations over three domain sizes subject to two different open ocean boundary forcings are compared to determine the influence of domain size on the computed response.

Results of this investigation clearly illustrate that storm surge model domains that are largely situated on the conti- nental shelf and whose domain size is limited relative to the size of the storm significantly underestimate the primary storm surge response. Significant storm surge occurs in the vicinity of open ocean boundaries of such domains when water is pushed up on the shelf by hurricane winds. Therefore, appropriate boundary conditions are difficult if not impossible to

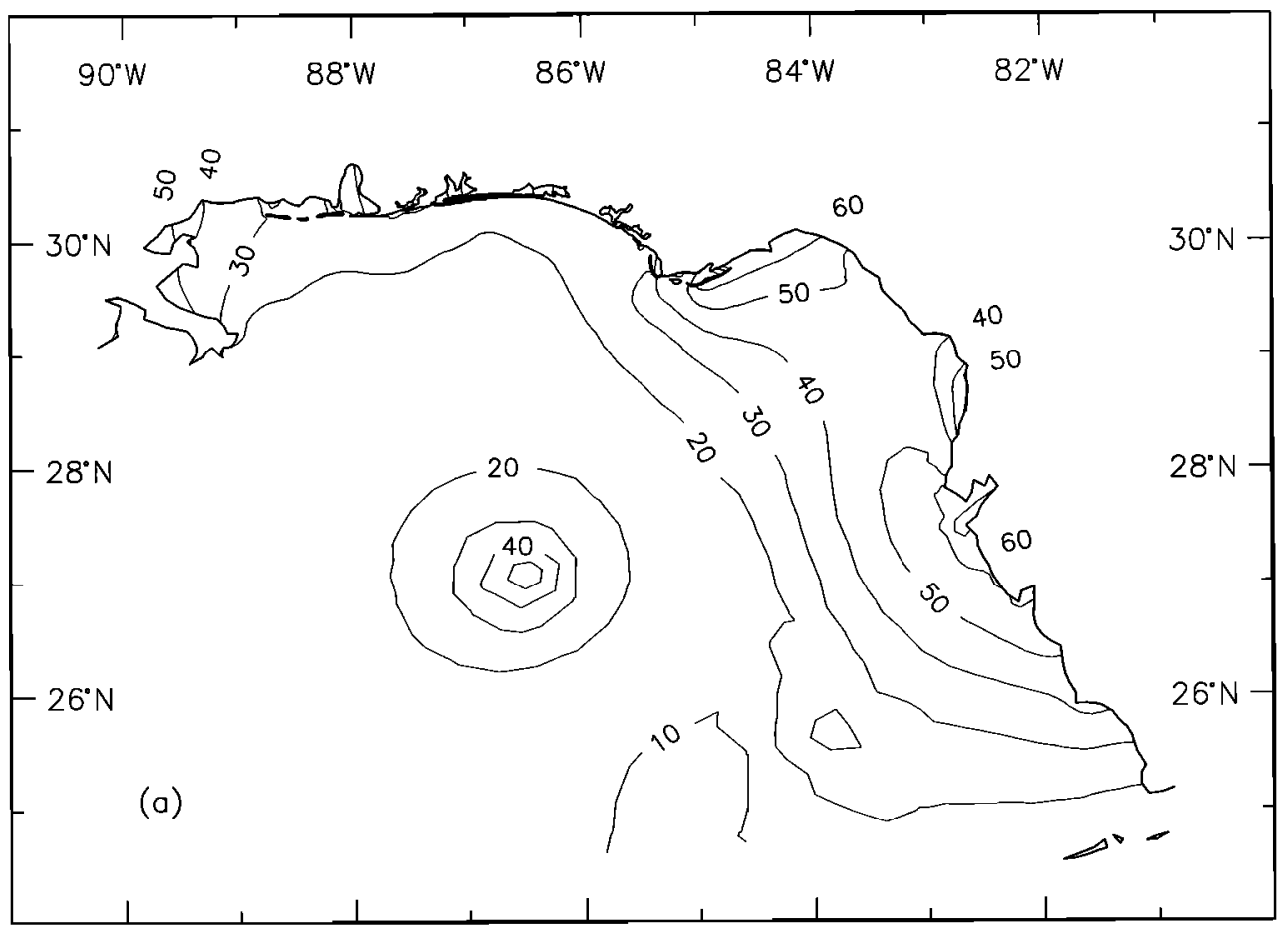

Figure 7a. Storm surge elevations in the northeast Gulf of Mexico due to Hurricane Kate on November 20, 1985, 2000 UT. 


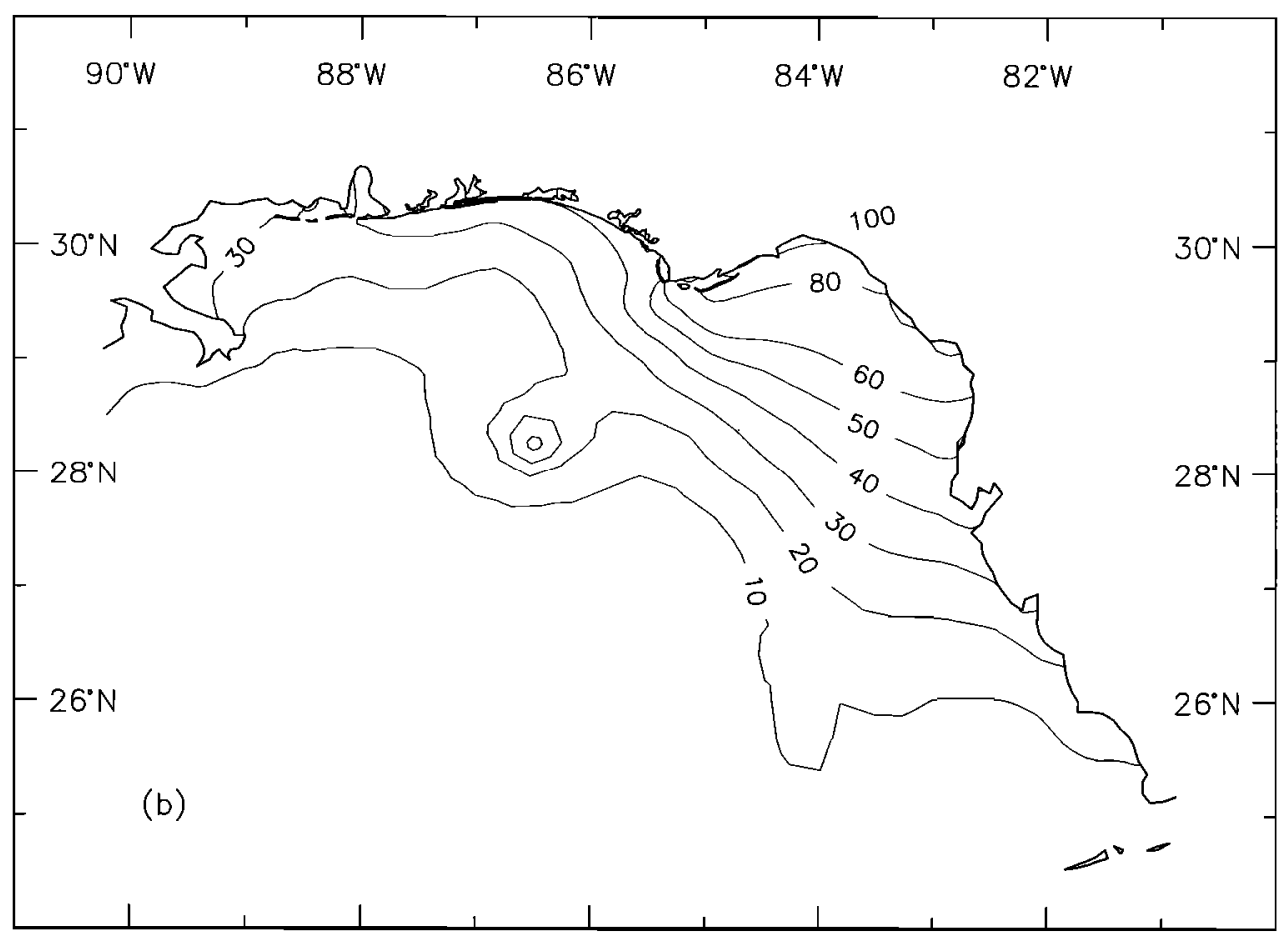

Figure 7b. Storm surge elevations in the northeast Gulf of Mexico due to Hurricane Kate on November 21, 1985, 0600 UT.

specify for these domains. Consequently, a significantly underestimated storm surge response results when using a small domain such as the Florida coast domain. Despite this, most storm surge modeling efforts to date have used similarly sized continental shelf domains, e.g., SLOSH model applications by the National Weather Service [Jarvinen et al., 1985; Jelesnianski et al., 1992].
The computed storm surge response over a domain which encompasses the Gulf of Mexico exhibits oscillatory behavior due to the existence of resonant modes or surge forerunner in the Gulf of Mexico basin. These resonant modes in the Gulf of Mexico are well documented and can be easily excited/influenced by a number of factors: the numerical discretization, start up conditions, the interior domain forcing functions, and/

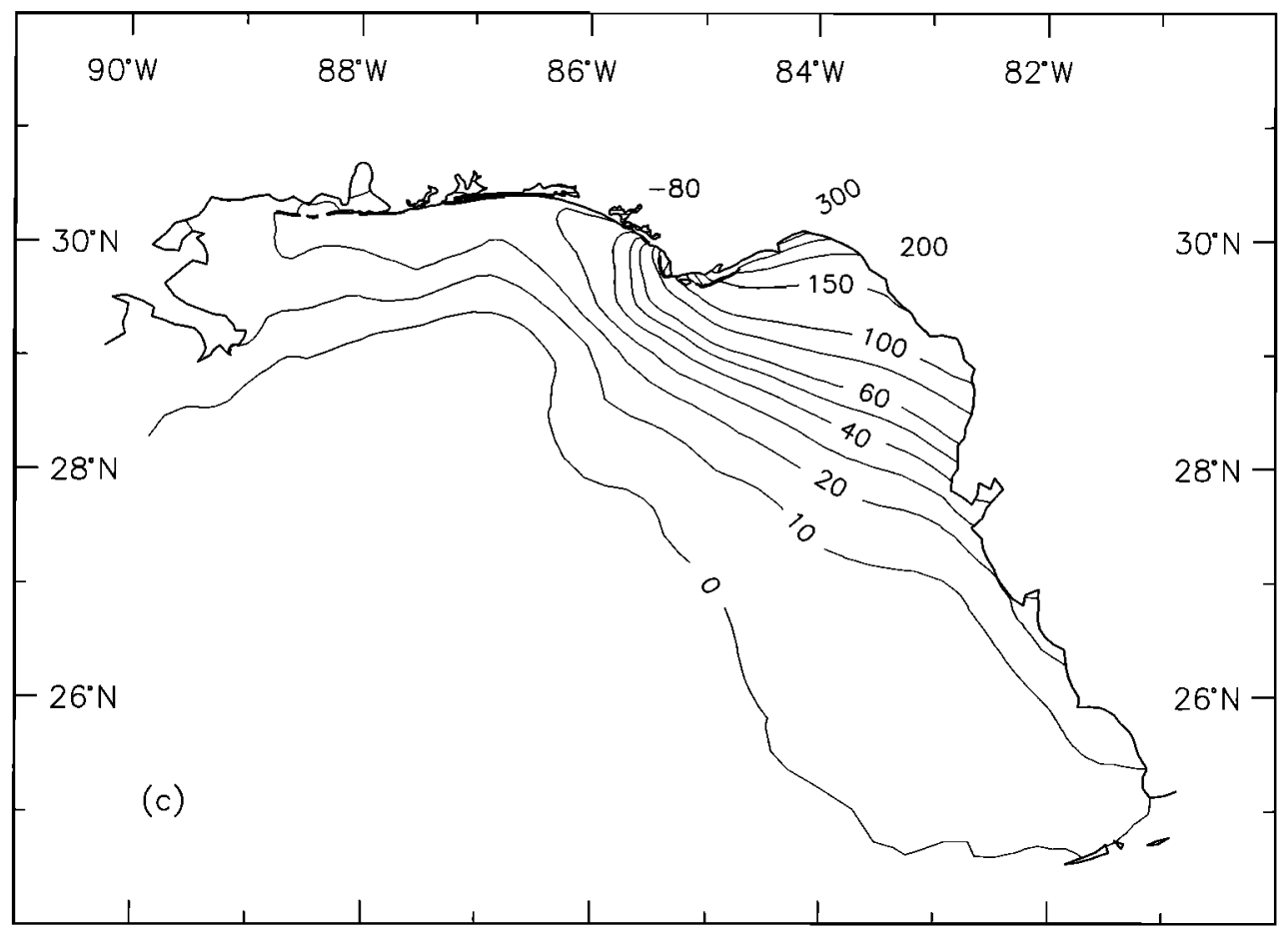

Figure 7c. Storm surge elevations in the northeast Gulf of Mexico due to Hurricane Kate on November 21, $1985,1800 \mathrm{UT}$. 
or the boundary conditions. This study reinforces the findings of others that resonant modes within the Gulf of Mexico are quite sensitive to boundary forcing functions specified over the Gulf of Mexico domain. Consequently, the storm surge response computed over the Gulf of Mexico domain may not capture the physics associated with the hurricane forerunner.

The Eastcoast domain, which includes the western North Atlantic Ocean, the Gulf of Mexico, and the Caribbean Sea, leads to convergent computations of both the primary storm surge and surge forerunner. A hurricane progresses through the domain generating and propagating storm surge in a natural and realistic fashion. The inclusion of contiguous basins allows proper setup of basin resonant modes and facilitates the realistic propagation of storm surge throughout the domain onto the continental shelf, where development of the storm surge is most critical. The main advantage of the Eastcoast domain is that the open boundaries lie within the deep Atlantic ocean and are far from the intricate processes occurring on the continental shelf and within the Gulf of Mexico basin in response to the storm. As was demonstrated, the sensitivity of coastal response to the open ocean meteorological boundary forcing is minimal.

The response characteristics of a storm surge model of the continental margin are profoundly influenced by the domain size and the associated boundary conditions. The amplitude of the primary surge varied significantly over the three domains examined. Furthermore, entire flow phenomena may be mere model artifacts and appear and disappear. In fact, a significant Helmholtz mode could be easily excited in the Gulf of Mexico model domain, while this is not the case in either of the other domains. Thus, in order to make meaningful statements about the physics, the modeler should be reasonably certain about the level of convergence that has been achieved, be it relative to grid discretization or, as in our study, domain size.

Acknowledgements. This research was supported by the U.S. Army Engineer Waterways Experiment Station under contract DACW-39-90-K-0021 and by the National Science Foundation under grant OCE-9116448. We thank A. M. Baptista of the Oregon Graduate Institute for allowing us to use the grid generation and visualization software packages XMGREDIT and XMVIS.

\section{References}

Bennett, J.R., and J.E. Campbell, Accuracy of a finite-difference method for computing lake currents, J. Comput. Phys., 68, 262-271, 1987.

Bunpapong, M., R.O. Reid, and R.E. Whitaker, An investigation of hurricane-induced forerunner surge in the Gulf of Mexico, Tech. Rep. CERC-85-5, Coastal Eng. Res. Cent, U.S. Army Eng., Vicksburg, Miss., Sept., 1985.

Cardone, V.J., C.V. Greenwood, and J.A. Greenwood, Unified program for the specification of hurricane boundary layer winds over surfaces of specified roughness, Report C.R.CERC-92-1, Coastal Eng. Res. Cent., U.S. Army Eng., Vicksburg, Miss., Sept., 1992.

Dietrich, D.E., A numerical study of small scale continental shelf features and their interactions with deep water flows, paper presented at the Conference on Mathematical and Computational Issues in the Geosciences, Soc. Int. Appl. Math., Houston, Tex., April 19-21, 1993.

Dietrich, D.E., P.I. Roache, and M.G. Marietta, Convergence studies with the Sandia Ocean Modeling System, Int. J. Numer. Methods Fluids, 11, 127-150, 1990.
Garratt, J.R., Review of drag coefficients over oceans and continents, Mon. Weather Rev., 105, 915-929, 1977.

Jarvinen, B.R., and M.B. Lawrence, An evaluation of the SLOSH storm-surge model, Bull. Amr. Meteoro. Soc., 11, 1408-1411, 1985.

Jarvinen, B.R., C.J. Neumann, and M.A.S. Davis, A tropical cyclone data tape for the North Atlantic Basin, 1886-1992, NOAA Data Tape, Natl. Ocean. and Atmos. Admin., Greenbelt, Md., 1993.

Jelesnianski, C.P., and A.D. Taylor, A preliminary view of storm surges before and after storm modifications, NOAA Tech. Memo. ERL WMPO-3, 1973.

Jelesnianski, C.P., J. Chen, and W.A. Shaffer, SLOSH: Sea, lake, and overland surges from hurricanes, NOAA Tech. Rep. NWS 48, 1992.

Kinnmark, I.P.E., The shallow water wave equations: Formulation, analysis and application, Ph.D. Dissertation, Dep. of Civil Eng., Princeton Univ., N. J., 1984.

Kolar, R.L., W.G. Gray, J.J. Westerink, and R.A. Luettich, Shallow water modeling in spherical coordinates: Equation formulation, numerical implementation, and application, $J$. Hydraul. Res., 32, 3-24, 1994a.

Kolar, R.L., J.J. Westerink, M.E. Cantekin, and C.A. Blain, Aspects of nonlinear simulations using shallow water models based on the wave continuity equation, Comput. Fluids, 23, 523-538, 1994b.

Le Provost, C., and P. Vincent, Some tests of precision for a finite element model of ocean tides, J. Comput. Phys., 65, 273-291, 1986.

Luettich, R.A., J.J. Westerink, and N.W. Scheffner, ADCIRC: An advanced three-dimensional circulation model for shelves, coasts and estuaries, Report 1: Theory and methodology of ADCIRC-2DDI and ADCIRC-3DL, Tech. Rep. DRP-92-6, Dep. of the Army, Washington, D.C., 1992.

Lynch, D.R., Progress in hydrodynamic modeling, Review of U.S. contributions, 1979-1982, Rev. Geophys., 21(3), 741754, 1983.

Lynch, D.R., and W.G. Gray, A wave equation model for finite element tidal computations, Comp. Fluids, 7, 207-228, 1979.

Piacsek, S., and R. Allard, The importance of horizontal resolution in coupled ice/ocean models of the arctic, paper presented at the Conference on Mathematical and Computational Issues in the Geosciences, Soc. Int. Appl. Math., Houston, Tex., April 19-21, 1993.

Platzman, G.W., Two dimensional free oscillations in natural basins, J. Phys. Oceanogr., 2(2), 117-130, 1972.

Reid, R.O., and R.E. Whitaker, Numerical Model for Astronomical Tides in the Gulf of Mexico, vol. 1: Theory and Application, Coastal Eng. Res. Cent., U.S. Army Eng., Vicksburg, Miss., 1981.

Westerink, J.J., R.A. Luettich, and J.C. Muccino, Modeling tides in the western North Atlantic using unstructured graded grids, Tellus, 46A, 187-199, 1994.

Westerink, J.J., and W.G. Gray, Progress in surface water modeling, Rev. Geophys., 29, suppl., 210-217, 1991.

C. A. Blain and J. J. Westerink (corresponding author), Department of Civil Engineering and Geological Sciences, University of Notre Dame, Notre Dame, IN 46556. (e-mail jjw@photius.ce.nd.edu)

R. A. Luettich Jr., University of North Carolina, Chapel Hill, Institute of Marine Sciences, 3431 Arendell Street, Morehead City, NC 28557. (e-mail UGTECH@uncvx1.oit.unc.edu)

(Received July 26, 1993; revised May 3, 1994; accepted May 5, 1994.) 